\title{
Microbial Community Dynamics in Field-Scale Biopile Bioremediation
}

\author{
Ana Maria Tănase ${ }^{1,2}$, Iulia Chiciudean², Ioana Mereuță $\breve{R}^{2}$ Robertina Ionescu², \\ Călina Petruța Cornea ${ }^{1}$, Tatiana Vassu ${ }^{2}$, Ileana Stoica ${ }^{2 *}$ \\ ${ }^{1}$ Molecular Biology Laboratory, University of Agronomic Sciences and Veterinary Medicine of Bucharest, \\ 59 Mărăşti Blvd, District 1, 011464, Bucharest, Romania \\ ${ }^{2}$ Department of Genetics, University of Bucharest, \\ 1-3 Portocalelor Aly, Districs 6, 060101, Bucharest, Romania
}

Received: 22 April 2016

Accepted: 12 August 2016

\begin{abstract}
Understanding the microbial communities responses to biopile procedures is an essential step in the field of microbial ecology and in bioremediation applications. In order to estimate metabolic dynamics at a microbial community level, we used Biolog Ecoplates. Assays showed that the bacterial communities from all samples were capable of utilizing a great variety from the 31 carbon substrates. Shannon's diversity index values were between $2.711 \pm 0.303$ in August and 3.262 \pm 0.062 in April, recording a general variation of 0.5 that is similar to other studies. Statistical analysis showed a good correlation coeficient for 2-hydroxybenzoic acid, a compound that is metabolized through the nafhthalene degradation pathway. Results showed a metabolic shift of the microbial community determined by temperature and the decrease of aromatic hydrocarbon concentrations. The shift was observed in the dynamics of MPN from 9x106 to $1 \times 10^{9}$ cell/g of soil. Even if the initial total petroleum hydrocarbon concentration from the biopile matrix was much higher than in other studies $(10.25 \mathrm{~g} / \mathrm{kg})$, at the end of the evaluation the pollutant content of the biopile matrix had a removal rate between $92-98 \%$ for monoaromatic hydrocarbons and $57-75 \%$ for poliaromatic hydrocarbons.
\end{abstract}

Keywords: bioremediation, metabolic dynamic, ECOplates, ANOVA, PCA, oil pollution

\section{Introduction}

A successful bioremediation program requires the application of several strategies tailored to the specific environmental parameters of the contaminated site, but also tailored to pollutant structure [1]. Pollution with oil compounds and oil sludge may cause a lot of damage

*e-mail: ileana.stoica@bio.unibuc.ro in many environments, having long-term effects due to their high toxicity and carcinogenic potential. One of the most useful low-cost, clean environmental tools in bioremediation of oil sludge is represented by biopile procedures [2-3]. This approach is based on indigenous microbial community metabolic activity, in order to degrade persistent and recalcitrant compounds with high molecular weight like polycyclic aromatic hydrocarbons (PAHs) [2, 4]. Many factors influence the ability of the microbial community to degrade high concentrations of 
various contaminants $[1,6]$, but the most important are temperature, oxygen, and moisture. Thus the study of metabolic specialization and metabolic dynamics might be essential for the discrimination of the microbial communities' abilities to degrade contaminants in order to remove them.

Measures of diversity and evenness have been used in several types of research to study substrate utilisation patterns from natural microbial populations in order to evaluate and predict the magnitude of microbial functional diversity [6]. A significant part of their proposed methods are based on isolation and characterization of microbial strains with specific metabolic activities within the communities, but knowing that most microbial strains are unculturable, the main conclusions are not even close to the real function and structure of the microbial community. In this regard, Biolog Ecoplates is a more advanced technique used to observe the potential activity of microbial communities and eliminate the limitation of conventional microbiological methods. Biolog Ecoplates generate reproducible patterns of carbon source utilization and provide the possibility of distinguishing temporal and spatial differences among microbial communities. [5, 7-8].

In this study, Biolog Ecoplates were used to evaluate the metabolic activity of microbial communities from a longterm oil polluted soil, in correlation with polyaromatic hydrocarbon concentrations, in a bioremediation project using field-scale biopile [1,6]. According to our knowledge, this was the first study regarding the metabolic changes of microbial communities as a response to various oil compound pollution for a 10-month period, analysing the community level physiological profiles (CLPP) in association with the decreasing concentration of several aromatic hydrocarbons and heavy metals. In the last few years Biolog Ecoplates have become a useful tool in soil microbial ecology and they are generally considered a sensitive fingerprinting tool for microbial communities' metabolic activity. However, no perfect method for processing and analyzing the huge amount of data has yet been found [9-10].

\section{Materials and Methods}

\section{Site Description}

An outdoor oil sludge storage site was chosen for this field experiment. This research was part of a larger remediation project involving a large area from Arges County, situated in a middle continental temperate zone area with temperatures in summer of $26-30^{\circ} \mathrm{C}$ and $-8^{\circ} \mathrm{C}$ in winter, and with annual precipitation of about $800 \mathrm{~mm} /$ $\mathrm{mp}$ with a maximum in May and June. A high amount of oil sludge was the result of different processes of oil exploitation. Aged oil sludge was dug out of the pools and mixed thoroughly using an excavator [11]. Then the sludge (about $82 \mathrm{mc}$ ) was divided into two piles, $\mathrm{S}(56.870 \mathrm{mc})$ and $\mathrm{N}(24.483 \mathrm{mc})$ and mixed with calcium sulfate, mechanically aerated.

\section{Field Sampling}

Samples were taken from mark places, on the first week of each month starting with March until December. When field sampling was conducted, four samples were taken, two from the north side and two more from the south side of the biopile. The $50 \mathrm{~g}$ sludge samples were stored at $4^{\circ} \mathrm{C}$ before subsequent analysis, but generally field samples were laboratory analyzed on the same day.

\section{Biolog Ecoplate}

Dynamics of the catabolic diversity of soil microbial community from the biopile was determined using a Biolog ECO microplate (Biolog, Inc., CA, USA). Samples were processed as previously using a 10-fold dilution and pre-mix in order to discharge microorganisms from the soil matrix. After 30 minutes of rest, $150 \mu \mathrm{l}$ of supernatant was inoculated to each well from a supplementary dilution of $10^{-2}$. Plates were incubated in the dark at $24^{\circ} \mathrm{C}$ and color development was monitored at $590 \mathrm{~nm}$ wavelength every $24 \mathrm{~h}$ for five days using an automated microtiterplate reader (Biolog Inc.). Because the plates were visibly colored by the addition of soil extract, the initial absorbances were measured immediately after inoculation and were subtracted from subsequent daily readings.

The average well color development (AWCD) for all carbon sources $[6,12]$ was calculated, being an indicator of total activity. Kinetic analysis also was performed using average well colour development (AWCD) as a parameter that enables us to capture an integral picture of sample differences in carbon source utilization. AWCD was calculated as the arithmetic mean of the OD values of all of the positive wells in the plate per reading time for all four samples $[7,13]$. AWCD means [6] for the three replicates on the same plate were calculated and then compared among each monthly soil sample. The AWCD can give an overall trend of metabolic activity of the microbial communities in time.

\section{Enumeration of Cultivable Bacteria}

The number of total cultivable bacteria were assessed by the plate count method. $5 \mathrm{~g}$ of fresh biopile sediment sample diluted in $45 \mathrm{~mL}$ sterile water was homogenized on a vortex mixer (S8A Stuart) at 2,200 rpm for $5 \mathrm{~min}$ shaken, repeated three times and then allowed to settle for $30 \mathrm{~min}$. Serial dilutions were made and plated in R2A (agar $15.0 \mathrm{~g}$, yeast extract $0.5 \mathrm{~g}$, acid hydrolysate of casein $0.5 \mathrm{~g}$, glucose $0.5 \mathrm{~g}$, soluble starch $0.5 \mathrm{~g}$, $\mathrm{K}_{2} \mathrm{HPO}_{4}, 0.3 \mathrm{~g}$, sodium pyruvate $0.3 \mathrm{~g}$, pancreatic digest of casein $0.25 \mathrm{~g}, \mathrm{MgSO}_{4}$ anhydrous $0.024 \mathrm{~g}$, and $\mathrm{pH}$ $7.2 \pm 0.2$ at $25^{\circ} \mathrm{C}$ ) for total heterotrophic bacteria (THB) [11]. The colony-forming units (CFU) of total cultivable microorganisms were recorded after incubation in the dark at $28^{\circ} \mathrm{C}$ for seven days and verified after 14 days for new colonies. Results were expressed per $\mathrm{ml}$ of 10 -fold initial dilution. 


\section{Chemical Analysis}

Polluted soil samples taken from the four sites were dried, ground, and sieved through a 2-mm mesh before analyzing any chemical composition. An independent private laboratory analyzed total aromatic hydrocarbons by SR-ISO 7877 [14], BTEX by SR-ISO 11423 [15], and polyaromatic hydrocarbons by SR-ISO 13877 [16] in order to determine soil quality [4]. The parameters of the ASE300 were set according to [11]. Determination of heavy metals $(\mathrm{Cd}, \mathrm{Cu}, \mathrm{Pb}, \mathrm{Ni}$ and $\mathrm{Zn})$ was performed according to SR EN ISO 17294 [17] using atomic absorption spectrometry $[1,11]$.

\section{Statistical Analysis}

Metabolic activity of microbial communities from the biopile was compared within diversity indexes, and AWCD performed based on the variance-covariance matrix. We used one-way ANOVA analyses with Tukey's post test to determine levels of significance using Minitab software. A level of 0.05 was used for the statistical Tukey test. To compare the CLPPs, we performed principal component analysis (PCA) using ecological analysis tools for microbial ecology (EATME) [18]. Correlations were performed using multiple linear regression with Pearson methods. Shannon's diversity index was calculated using data from the $\mathrm{DO}_{590}$ after subtraction of water blank values, where $p i$ is the ratio of the contribution of each individual substrate to the sum of DO from all substrates, and is used to assess the evenness of functional diversity $[6,9]$.

\section{Results and Discussions}

\section{Dynamics of Metabolic Capacities of Microbial Community}

In most studies, the soil samples have been collected from replicated treatment plots or from different kinds of ecosystems. In this study we collected four samples (D1S1, D1S2, D1N1, and D1N2) flag-marked from the same biopile and analyzed for 10 months. Biolog EcoPlate assays showed that the bacterial communities from all samples utilized a variety of the 31 carbon substrates, grouped in the following classes of compounds: amines, carbohydrate complex carbon sources, carboxylic acids, amino acids, and phosphate carbon according to similar studies [7, 19-20]. The utilization of carbon sources into six substrate groups showed similar use every month, despite the temperature variations between cold and extremely hot seasons.

Utilization of carbon sources calculated as AWCD (average color) [7] (Fig. 1), and showed a sigmoidal trend of microbial community metabolic activity and response. Similar studies underlined that AWCD values could reflect the oxidative capacity of soil microorganisms developing in the Biolog Microplates and is usually used as an indicator of overall microbial activity from the location

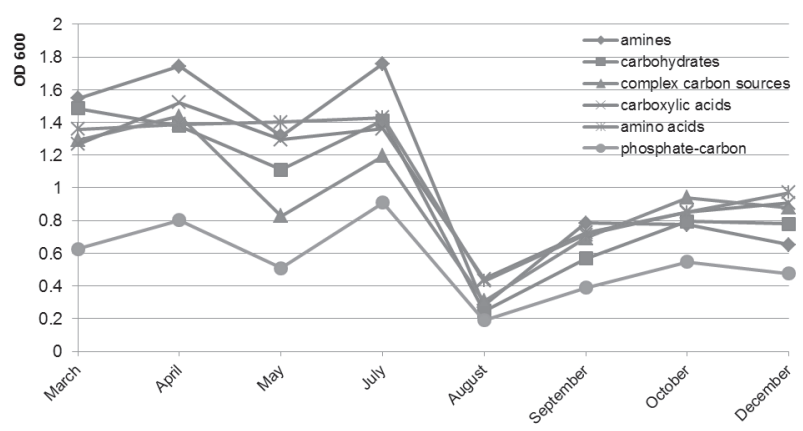

Fig. 1. Dynamics of microbial community metabolic abilities from the biopile for each carbon souce group over 10 months.

of samples [7]. In our study this is an indication of a high oxidative potential of biodegradative activity of the microbial community, the decreasing AWCD values from august can be due to high ambient average temperature, which caused a strong dehydration in the biople matrix. The autumn and winter months also registered a low metabolic activity due to decreasing pollutants, microbial community selected until that time being most probably specialized on such compounds. AWCD shows the fastest rate of carbon substrate consumption, suggesting great genetic diversity within the analized bacterial community $[3,19,21]$.

Shannon's diversity index values were between $2.711 \pm 0.303$ in August and 3.262 \pm 0.062 in April, registering a general variation of 0.5 that is similar to other studies that evaluated this index in different environments. Surprisingly, the biodegradative community from our study presented a higher diversity index than those reported in grassland (2.26 \pm 0.31 and $2.92 \pm 0.23)$ [21].

In most studies, the soil samples are collected from replicated treatment plots or from different kinds of ecosystems [11, 21], but we compared diversity indices within each month using a two-way analysis of variance (ANOVA) using the three replicates from Ecoplates and all four locations for all 31 carbon sources. All substrates analyzed supported the growth of the microbial communities of biopile in every sampling time studied. ANOVA of $\mathrm{H}$ revealed that the data is statistically significant for each moment of prelevation with a $\mathrm{p} \leq 0.001$, and Tukey test grouped all moments of sampling except August, which seems to have a different metabolic activity. ANOVA on AWCD also revealed that all data are statistically significant with a $\mathrm{p}<0.001$ but were detected in three groups A--> March, May, April, July; B-->March, July, December, October; and C --> December, October, September, August. When we applied logarithmic Pearson correlation of those data in the EATME online software package, the three groups remained the same.

In order to distinguish the carbon utilization patterns of biopile microorganisms, PCA of substrate utilization patterns was performed using a Pearson correlation from EATME. The correlation matrix generated indicated that phenyl ethyl-amine is the carbon source having the biggest correlation coefficient of 0.76 (G4) with PC1 (Fig.2), 
which can be explained on the one hand by its presence in the biopile matrix because it is a plant component, and on the other hand is a compound that can be produced by several bacterial strains as an antimicrobial substance. Another good correlation coefficient with $\mathrm{PCl}$ was observed for the D-xylose 0.70 (B2) derivate of hemicellulose - one of the main constituents of plant biomass. The microbial community from biopile was shown to be able to metabolise 2-hydroxybenzoic acid (salicylic acid) and the isomer form 4-hydroxybenzoic acid, having a good correlation 0.70 and 0.57 , respectively, that was expected because it is believed that a majority of bacteria are able to use salicylic acid, which is an intermediate in the naphthalene pathway, possess the enzyme required for the degradation of naphthalene or certain tricyclic aromatic hydrocarbons $[2,10]$.

\section{Enumeration of Cultivable Bacteria}

The previous results are also sustained by the number of cultivable microorganisms forming units from soil samples, presented in Fig. 3. At the start of bioremediation processes, in March, the total heterotrophic bacterial average number was $9 \times 10^{6}$, and after one month of bioremediation procedures the average number was much higher in April and May, with $1 \times 10^{9}$ cell/g of soil. These may be because of optimal ambient temperatures with an average of $10-12^{\circ} \mathrm{C}$, but also the availability of carbon sources, even those sources represented by aromatic hydrocarbons and also the water availability in spring. In July and August, metabolic activity and most probable number were drastically decreased mostly because of the high daytime temperature of almost $40^{\circ} \mathrm{C}$ that had major implications on water availability in the biopile matrix. In autumn months the average number of cultivable

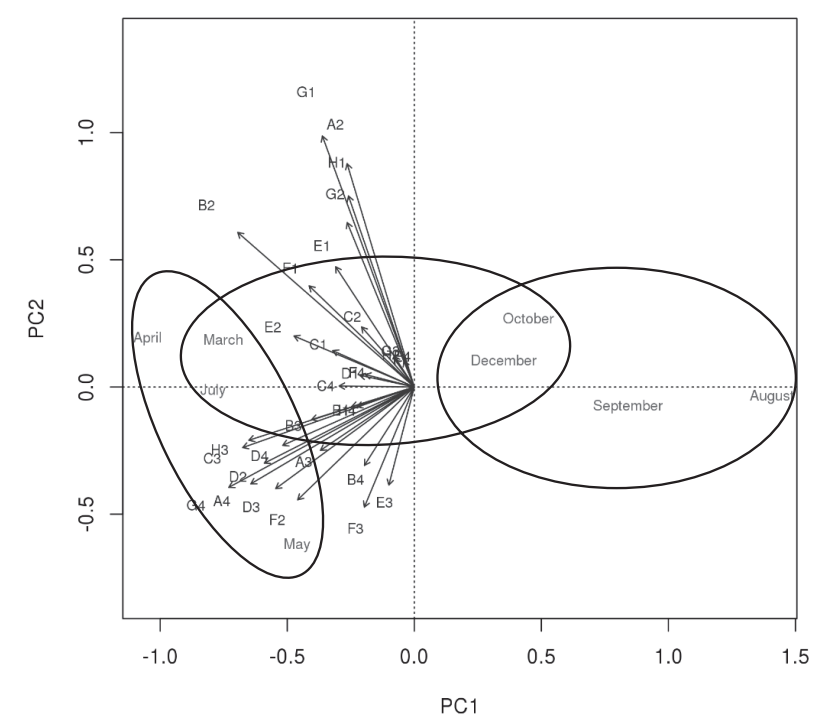

Fig. 2. Principal component analysis on data of activity on carbon sources in Biolog EcoPlates from each month of biopile sampling. (A2-H4 are the carbon sources from the first EcoPlates replicate, acording to their position on the plate.) bacteria was slightly decreasing because the carbon source concentrations were significantly lower. Several authors reported that organic management practices may lead to increased soil microbial biomass activity and microbial functional and taxonomic richness and diversity when compared to conventional farming [22-23]. Several environmental studies have mentioned differences in heterotrophic bacterial number in natural ecosystems, raising between $1 \times 10^{11}$ and $5 \times 10^{12}$ culturable microorganisms in grassland soil [24] and naphthalene degrader microorganisms in soil, between $2.2 \times 10^{3}$ and $1.5 \times 10^{4}$ cells/g or average MPN counts obtained from the oil-contaminated soil ranged $2.1 \times 10^{5}$ cells/ $\mathrm{g}$ of soil [23] or $6 \times 10^{4} \mathrm{PAH}-$ degrading bacteria/g of soil in a microcosm during experimental biostimulation procedures [25].

\section{Chemical Analysis}

Aromatic hydrocarbons analysis revealed very high concentrations at the start of this study compared with other reports $[4,26,27]$. The initial concentration of pollutants, from March, was very high: total petroleum hydrocarbon $10.25 \mathrm{~g} / \mathrm{kg}$, BTEX $18.33 \mathrm{mg} / \mathrm{kg}, \mathrm{PAH}$ $442.75 \mathrm{mg} / \mathrm{kg}$, and TOC $72.5 \mathrm{~g} / \mathrm{kg}$. Components determined initially had the following values: naphthalene $65.05 \mathrm{mg} / \mathrm{kg}$, benzene $0.56 \mathrm{mg} / \mathrm{kg}$, toluene $1.23 \mathrm{mg} / \mathrm{kg}$, ethylbenzene $3.38 \mathrm{mg} / \mathrm{kg}$, xylene $11.2 \mathrm{mg} / \mathrm{kg}$, anthracene $17.59 \mathrm{mg} / \mathrm{kg}$, fluoranthene $75.7 \mathrm{mg} / \mathrm{kg}$, and benzo(a)anthracene $27.43 \mathrm{mg} / \mathrm{kg}$; heavy metals detected were lead $40.23 \mathrm{mg} / \mathrm{kg}$, cadmium $1.75 \mathrm{mg} / \mathrm{kg}$, zinc $511.25 \mathrm{mg} / \mathrm{kg}$, copper $82.75 \mathrm{mg} / \mathrm{kg}$. Despite the high amount of pollu-tants, the mean $\mathrm{pH}$ value was 7.5 an almost ideal condition for microbial community bioremediation process.

At the end of the monitoring, the pollutant content of the biopile matrix had between 92-98\% removal of monoaromatics hydrocarbons and between $57-75 \%$ removal of polyaromatic hydrocarbons [2]. On the other hand, heavy metals persist, lead concentration did not register any significant modification, and cadmium, copper, and zinc concentrations were reduced only by $9-16 \%$ from initial levels. Correlation analysis of all contaminants detected in the biopile showed good correlation values for

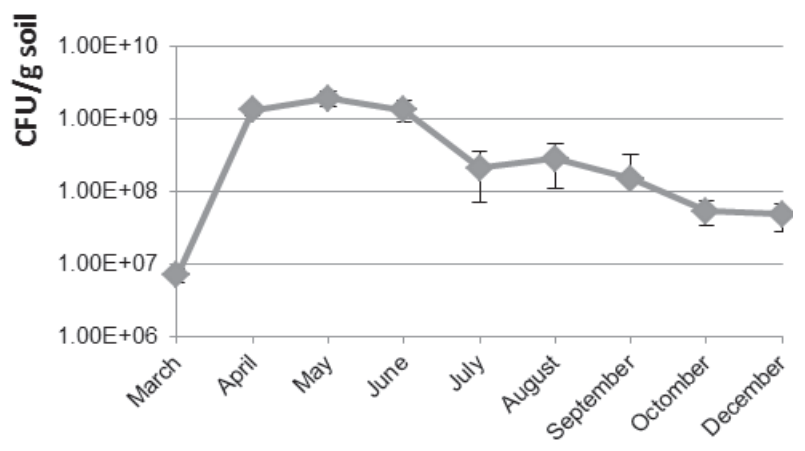

Fig. 3. The average MPN count of four replicates obtained from the oil-contaminated biopile. 
toluene, benzene, and ethylbenzene and xylene $\mathrm{R}=0.95$ $(\mathrm{p}<0.01$; maybe due to their similar catabolic pathways in microbial cells), and also between naphthalene, phenanthrene $\mathrm{R}=0.80 \quad(\mathrm{p}<0.01)$ and fluoranthene, anthracene $\mathrm{R}=0.88(\mathrm{p}<0.01)$. Another aspect that can be underlined is that polyaromatic hydrocarbon removal had a good correlation with $\mathrm{pH}$ value. As mentioned in other studies [11], this seemed to be a relationship between the removal of $\mathrm{Cu}$ and $\mathrm{Zn}$, in our study having a correlation coefficient of $\mathrm{R}=0.87(\mathrm{p}<0.01)$, but initial concentration was five times higher.

\section{Conclusions}

The biopile approach in this case study, for oil compound removal, was a successful technique in order to eliminate polyaromatic hydrocarbons by endogenous microbial community biodegradation. The dynamics of metabolic capacities indicated a high activity of microorganisms capable of utilized complex carbon sources. Moreover, correlations were found between metabolic pathways and naphthalene-decreasing concentrations. An increasing number of microbial cells per $\mathrm{g}$ of soil and pollutants decreasing concentrations indicated a high metabolic activity, especially for aromatic hydrocarbon degraders. Even if in our data statistical analysis does not retrieve any correlation between metabolics and the number of microbial community or ambient temperature, most papers seem to underline the importance of seasonal temperature changes.

\section{Acknowledgements}

This paper was published under the framework of the European Social Fund, Human Resources Development Operational Programme 2007-13, project No. POSDRU/159/1.5/S/132765.

\section{References}

1. BALDAN E., BASAGLIA M., FONTANA F., SHAPLEIGH J. P., CASELLA S. Development, assessment and evaluation of a biopile for hydrocarbons soil remediation International Biodeterioration \& Biodegradation. 98, 66, 2015.

2. ALISI C., MUSELLA R., TASSO F., UBALDI C., MANZO S., CREMISINI C., ROSA SPROCATI A. Bioremediation of diesel oil in a co-contaminated soil by bioaugmentation with a microbial formula tailored with native strains selected for heavy metals resistance, Science of the Total Environment. 407, 3024, 2009.

3. TĂNASEA-M., MEREUTAI., CHICIUDEAN I., IONESCU R., CORNEA C.P., VASSU T., STOICA I Metabolic and molecular dynamics of microbial communities from kerosene polluted microcosm. Journal of Biotechnology. 208, Supplement, S64, 2015.

4. AICHNER B., BUSSIAN B. M., LEHNIK-HABRINK P., HEIN S. Regionalized concentrations and fingerprints of polycyclic aromatic hydrocarbons (PAHs) in German forest soils Environmental Pollution. 203, 31, 2015.

5. CHEN J., XIE H., ZHUANG X., ZHUANG G., BAI Z., ZHANG H. Substrate-induced changes in microbial community-level physiological profiles and their application to discriminate soil microbial Communities. Journal of Environmental Sciences. 20, 725, 2008.

6. AL-MUTAIRI N.Z. Variable distributional characteristics of substrate utilization patterns in activated sludge plants in Kuwait, Bioresource Technology. 100, 1524, 2009.

7. TIQUIA S.M. Metabolic diversity of the heterotrophic microorganisms and potential link to pollution of the Rouge River. Environ. Pollut. 158, 1435, 2009.

8. TĂNASE A.M., MEREUTA I., CHICIUDEAN I., IONESCU R., MILEA L., CORNEA C.P., VASSU T., STOICA Comparison of total DNA extraction methods for microbial community from polluted soil I. Agriculture and Agricultural Science Procedia. 6, 616, 2015.

9. BRADLEY R.L., SHIPLEY B., BEAULIEU C. Refining numerical approaches for analyzing soil microbial community catabolic profiles based on carbon source utilization patterns. Soil Biology \& Biochemistry. 38, 629, 2006.

10. STEFANOWICZ A. The Biolog Plates Technique as a Tool in Ecological Studies of Microbial Communities A. Polish J. of Environ. Stud. 15 (5), 669, 2006.

11. CHEN L., CAI Q., XU S., LIU X., CHEN S. Distributuion characteristics, pollution assessment and source identification of heavy metals in sediments of Wetland Lakes. Pol.J. Environ.Stud. 24, 1525, 2015.

12. WANG X., WANG Q., WANG S., LI F., GUO G. Effect of biostimulation on community level physiological profiles of microorganisms in field-scale biopiles composed of aged oil sludge Bioresource Technology. 111, 308, 2012.

13. SANDERS J.G., SPLIID H., ALBRECHTSEN H.J., Microbial Community-Level Physiological Profiles (CLPP) and herbicide mineralization potential in groundwater affected by agricultural land use. Journal of Contaminant Hydrology 140, 45, 2012.

14. Roumanian Stadard ISO SR 7877-2:1995 Determination of total petroleum hydrocarbons from suspentions Part 2: Method using spectrofotmetry.

15. Roumanian Stadard ISO 11423-2:1997 Water quality -- Determination of benzene and some derivatives -- Part 2: Method using extraction and gas chromatography

16. Roumanian Stadard SR-ISO 13877:1998. Soil quality -- Determination of polynuclear aromatic hydrocarbons -- Method using high -performance liquid chromatography

17. SR EN ISO 17294-2:2003 Water quality -- Application of inductively coupled plasma mass spectrometry (ICP-MS) -Part 2: Determination of 62 elements.

18. https://www.microb3.eu/sites/default/files/deliverables/ MB3_D5_9_PU.pdf.

19. CARDINALI-REZENDE J., MORAES A.M.M., COLTURATO L.F.D.B., CARNEIRO E.V., MARRIEL I.E. CHARTONE-SOUZA E., NASCIMENTO A.M. A. Phylogenetic and physiological characterization of organic waste-degrading bacterial communities. World J Microbiol Biotechnol. 27, 245, 2011.

20. LEE E.H., KIM J., KIM J.Y., KOO S.Y., LEE S.D., KO K.S., KO D.C., YUM B.W., CHO K.S. Comparison of microbial communities in petroleum-contaminated groundwater using genetic and metabolic profiles at Kyonggi-Do, South Korea. Environ Earth Sci 60, 371, 2010.

21. FANG H., YU Y.,CHU X., WANG X., YANG X., YU J. Degradation of chlorpyrifos in laboratory soil and its impact on soil microbial functional diversity. Journal of Environmental Sciences. 21, 380, 2009. 
22. STEFANOWICZ A. The Biolog Plates Technique as a Tool in Ecological Studies of Microbial Communities A. Polish J. of Environ. Stud. 15 (5), 669, 2006.

23. LOPES A.R., FARIA C., PRIETO-FERNÁNDEZ A., TRASAR-CEPEDA C., MANAIA C.M., NUNES OLGA C. Comparative study of the microbial diversity of bulk paddy soil of two rice fields subjected to organic and conventional farming. Soil Biology \& Biochemistry. 43, 115, 2011.

24. WALLENIUS K, LAPPI K, MIKKONEN A, WICKSTRÖM A, VAALAMA A, LEHTINEN T, SUOMINEN L. Simplified MPN method for enumeration of soil naphthalene degraders using gaseous substrate. Biodegradation. 23, 47, 2012.

25. GRAHAM M.H., HAYNES R.J. Catabolic diversity of soil microbial communities under sugarcane and other land uses estimated by Biolog and substrate-induced respiration methods. Applied Soil Ecology. 29, 155, 2005.

26. TENG Y., LUO Y., SUNM., LIU Z., LI Z., CHRISTIE P., Effect of bioaugmentation by Paracoccus sp. strain HPD-2 on the soil microbial community and removal of polycyclic aromatic hydrocarbons from an aged contaminated soil. Bioresource Technology. 101, 3437, 2010.

27. MELNYK A., DETTLAFF A., KUKLIŃSKA K., NAMIEŚNIK J., WOLSKA L. Concentration and sources of polycyclic aromatic hydrocarbons (PAHs) and polychlorinated biphenyls (PCBs) in surface soil near a municipal solid waste (MSW) landfill. Science of the Total Environment. 530, 18, 2015. 